\title{
A PESQUISA NO CURRÍCULO DE UM CURSO DE FORMAÇÃO INICIAL DOS PROFESSORES DE EDUCAÇÃO FÍSICA
}

\author{
Néri Emilio Soares Junior \\ Universidade Estadual de Goiás, Goiânia, Goiás, Brasil
}

Resumo: O presente estudo tem o objetivo de analisar o lugar da pesquisa no currículo de um curso de formação inicial de professores de Educação Física para a Educação Básica. Para alcançar tal propósito procuramos compreender se a pesquisa é componente integrante nas Diretrizes Curriculares Nacionais para a Formação de Professores para a Educação Básica e analisamos a concepção e a indicação de inclusão da pesquisa estabelecida no projeto político pedagógico do curso de formação. Foi utilizado como procedimento de pesquisa a análise documental. A pesquisa foi realizada em curso de formação de professores de Educação Física vinculada a uma universidade localizada no Estado de Goiás.

Palavras-chave: Educação física, formação inicial, currículo, pesquisa.

\section{Apresentação}

Este artigo apresenta resultados de uma investigação realizada para realização de uma dissertação de mestrado intitulada: O lugar da pesquisa no currículo da formação inicial dos professores da Educação Física (SOARES JÚNIOR, 2010) e insere-se em torno do debate sobre a formação docente, mais especificamente a pesquisa na formação inicial de professores.

Apesar desse tema ser recorrente na Educação e ser objeto de várias pesquisas nessa área, principalmente a partir da década de 1990 (PIMENTA, 2006), ainda são escassos os estudos sobre essa temática na Educação Física (SOARES JÚNIOR, 2010). Aliado a esse fato, a Educação Física teve em sua história uma forte influência da racionalidade técnica ${ }^{1}$ nos currículos dos cursos de formação de professores (BORGES, 1998; TAFFAREL, 1993; TAFFAREL et al., 2006), o que contribuiu para uma inserção pouco edificante da pesquisa em seus programas de formação docente.

${ }^{1}$ A racionalidade técnica é um paradigma herdado do positivismo (PÉREZ GÓMEZ, 1992) que concebe a atividade profissional direcionada a solução de problemas mediante a aplicação de técnicas. Os professores são considerados executores de técnicas e reprodutores de conhecimento. A pesquisa, nesse modelo, é separada institucionalmente prática (TARDIF, LESSARD, GAUTHIER, s.d.), o que torna incompatíveis as atividades de ensino e pesquisa. A formação docente é concebida como um modelo de transmissão de conhecimentos e os seus currículos são organizados de forma linear, fragmentada e hierarquizada e sem lugar para a pesquisa. 
E, a partir desta problemática houve interesse em analisar o lugar da pesquisa no currículo de um curso de formação de professores para a Educação Física. Sendo assim, procurou-se responder a seguinte questão: qual é o lugar da pesquisa nas Diretrizes Curriculares Nacionais para a formação de professores para a Educação Básica e no projeto político-pedagógico de um curso de formação inicial de professores de Educação Física para a Educação Básica?

Nesse texto temos como objetivos: a) compreender se a pesquisa é componente integrante nas Diretrizes Curriculares Nacionais para a Formação de Professores de Educação Física para a Educação Básica e, b) analisar a concepção e a indicação de inclusão da pesquisa estabelecida no projeto político pedagógico do curso de formação.

A definição metodológica da pesquisa foi orientada pela ideia de que o currículo, que surge em um curso de formação docente, é resultado de um processo complexo construído em um contexto sócio-histórico, no qual diferentes sujeitos, defendendo seus diferentes projetos políticos, culturais e sociais, lutam "[...] pela oficialização e pelo prestígio de seus conhecimentos, significados, habilidades, métodos, crenças e valores" (MOREIRA, 2005, p.16). As lutas estabelecidas nesse campo que configuram o currículo se materializam em diferentes níveis em que ocorrem as tomadas de decisões. Essas decisões acontecem desde orientações estabelecidas pelas políticas públicas educacionais, até as salas de aula das instituições de ensino (GIMENO SACRISTRÁN, 2000).

Em nosso estudo a pesquisa científica é considerada como meio de produção de conhecimento (GATTI, 2007; LÜDKE; ANDRÉ, 2005), que procura explicar fatos da realidade a partir de estratégias fundamentadas por um determinado método (LÜDKE; ANDRÉ, 2005; GAMBOA, 2007). É importante considerar que esse conhecimento produzido deve superar a aparência, o senso comum.

\section{O percurso da investigação}

Realizamos a análise documental do projeto pedagógico de uma instituição pública no Estado de Goiás. Para resguardar o anonimato da instituição e daqueles que lá desenvolvem suas atividades não será divulgado seu nome. Usaremos então, o nome genérico: "Instituição Formadora".

Foi analisado o conjunto de documentos que representam os diferentes níveis de decisão curricular. De uma forma geral, esses níveis ocorrem em três contextos diferentes: o político-administrativo, que se materializa em diversas orientações oficiais na forma de pareceres, resoluções e diretrizes para os cursos de educação superior; projeto educativo da instituição educacional; e o plano de ensino do professor no contexto da aula (GIMENO SACRISTÁN, 2000). Assim foram analisados:

a) Os Referencias para formação de professores; o Parecer CNE/CP n ${ }^{\circ}$. 09/2001 e a Resolução CNE/CP $n^{0}$. 01/2002, que instituiu as Diretrizes Curriculares Nacionais para a formação de professores da Educação Básica, em nível superior, curso de licenciatura, graduação plena; a Resolução $\mathrm{CNE} / \mathrm{CP} \mathrm{n}^{0}$. 02/ 2002, que instituiu a duração e a carga horária dos cursos de licenciatura, de graduação plena, de formação de professores da Educação Básica em nível superior. 
b) O projeto político pedagógico do curso de Licenciatura da Instituição Formadora e as ementas de todas as disciplinas.

c) Os planos de curso de 9 disciplinas que possuem indicação de inclusão da pesquisa.

\section{A Pesquisa nas Diretrizes Curriculares Nacionais para formação de professores para a Educação Básica}

A partir da análise documental, foi compreendido que a pesquisa está incluída nas Diretrizes Curriculares Nacionais para formação do professor para Educação Básica como um dos seus princípios norteadores para o preparo e o exercício profissional. (BRASIL, 2001). Mas a concepção de pesquisa posta nas diretrizes está aprisionada ao processo de ensino/aprendizagem. Vejamos um trecho dos Referenciais para a Formação de Professores (BRASIL, 1999):

E quando investiga, reflete, seleciona, planeja, organiza, integra, avalia, articula experiências, recria e cria formas de intervenção didática junto aos seus alunos, para que eles avancem em suas aprendizagens, que ele produz conhecimento pedagógico. Assim, a investigação que o professor realiza se diferencia da pesquisa acadêmica pela sua natureza e intencionalidade: quando se toma a prática, em toda a sua complexidade, como objeto para a reflexão, constitui-se um campo de conhecimento que é específico do professor. A atitude investigativa dos professores é um mergulho no mundo complexo da prática pedagógica, no qual ele se envolve afetiva e cognitivamente, questionando as próprias crenças, propondo $\mathrm{e}$ experimentando alternativas. É um trabalho de levantar hipóteses, buscar dados para compreender aspectos de situações singulares ou encaminhamentos generalizáveis em sala de aula, como a constituição de boas situações de aprendizagens de alguns conteúdos específicos. (p.108, grifos nossos).

A diferenciação entre a pesquisa do professor e a pesquisa científica configurase aqui como um descomprometimento da produção realizada pelos professores com a pesquisa científica ou acadêmica:

Com esses instrumentos, poderá, também, ele próprio, produzir e socializar conhecimento pedagógico de modo sistemático. Ele produz conhecimento pedagógico quando investiga, reflete, seleciona, planeja, organiza, integra, avalia, articula experiências, recria e cria formas de intervenção didática junto aos seus alunos para que estes avancem em suas aprendizagens. (BRASIL, 2001 p.36).

Neste processo, a construção de conhecimentos acontece a partir do cotidiano escolar:

Assim, a pesquisa constitui um instrumento de ensino e um conteúdo de aprendizagem na formação, especialmente importante para a

Pensar a Prática, Goiânia, v. 14, n. 1, p. 1-12, jan./abr. 2011 
análise dos contextos em que se inserem as situações cotidianas da escola, para construção de conhecimentos que ela demanda e para a compreensão da própria implicação na tarefa de educar. Ela possibilita que o professor em formação aprenda a conhecer a realidade para além das aparências, de modo que possa intervir considerando as múltiplas relações envolvidas nas diferentes situações com que se depara, referentes aos processos de aprendizagem e à vida dos alunos. (BRASIL, 2001, p.36).

Dessa forma, mediante a ação reflexiva o professor produz saberes, e ao ter a prática como cerne deste processo, é o único capaz de refletir sobre ela:

A literatura sobre o professor pesquisador centra-se, portanto, na consideração da prática, que passa a ser meio, fundamento, origem e destinação dos saberes que suscita, desde que esses possam ser orientados e apropriados pela ação reflexiva do professor. Só o seu detentor, o professor, está em condições de refletir sobre ela. Ele pode e deve considerar os cursos vindos de forma para orientar sua ação reflexiva, mas é fundamentalmente de dentro que ele a constrói. Assim procedendo, produz teorias válidas não só para se orientar, mas também para constituir uma ciência prática que se equipare à ciência produzida pelos acadêmicos. (MIRANDA, 2001, p.135).

Abandonando a totalidade de um conhecimento universal centrado na ciência, a relação teoria/prática inclina-se para a prática, não sendo os fundamentos teóricos considerados importantes e a ênfase do ensino se dá com a reflexão "na" e "sobre" a prática. Vejamos a indicação do processo de reflexão no curso de formação indicado nos Referenciais para Formação de Professores:

A importância dessas aprendizagens indica que o exercício de reflexão sobre a prática, isto é, de tematizá-la em seus múltiplos aspectos, tomando-a como objeto de reflexão organizada e compartilhada, deve ser sistemático desde o início do curso de formação inicial de professores e ao longo de todo o processo de formação continuada.

A tematização da prática está diretamente vinculada à concepção de professor reflexivo, que toma sua atuação como objeto para a reflexão. (BRASIL, 1999, p.109).

E esse enfoque pragmático se coaduna com a Resolução CNE/CP n ${ }^{\circ}$. 02/2002, que constitui a carga horária mínima para os cursos de Licenciatura com um número reduzido nas horas para as disciplinas relacionadas aos fundamentos teóricos. A referida Resolução estabelece 2800 horas como carga horária mínima de curso, com 400 horas de prática como componente curricular, 400 horas de estágio curricular supervisionado a partir da segunda metade do curso, 1800 para conteúdos curriculares de natureza científico-cultural e 200 horas para outras formas de atividades acadêmico-científicoculturais. A carga horária destinada a "prática como componente curricular" e outras formas de atividade acadêmico-científico-culturais é muito alta em detrimento de uma pequena carga horária das disciplinas curriculares de natureza científico-cultural.

Pensar a Prática, Goiânia, v. 14, n. 1, p. 1-12, jan./abr. 2011 
A perspectiva da inclusão de pesquisa nas políticas curriculares está relacionada com as políticas públicas de formação de professores desenvolvida a partir das reformas educacionais implantadas no Brasil no bojo das políticas neoliberais. Nessa lógica, a ênfase da formação docente é de caráter pragmático e instrumental, expressando-se numa formação inicial aligeirada, compreendida apenas como capacitação técnica, em que o professor aprende o fazer pedagógico sem compreender seus fundamentos (KUENZER, 2008, VEIGA 2009).

\section{A pesquisa no projeto pedagógico do curso de licenciatura da Instituição Formadora}

No curso de Licenciatura ofertado na Instituição Formadora apresentou a carga horária para integralização curricular no ano de 2009 de 3.516 horas, com duração mínima de 8 semestres e máxima de 14. A organização do regime acadêmico do curso é semestral.

No projeto político-pedagógico da Instituição Formadora apresenta a concepção de pesquisa como instrumento de produção de conhecimento e parte da formação docente e da intervenção profisssional.

Também está posta como princípio nuclear do curso e eixo orientador das ações dos professores e estudantes. Como forma para assegurar a operacionalização desta articulação, o projeto político pedagógico prevê que as disciplinas de conteúdos sejam concebidas como espaços temáticos de conhecimento, isso requer eliminar a utilização do pré-requisito nas disciplinas. A ideia é romper com a relação de dependência dos conteúdos; assim, cada disciplina é concebida como tema gerador específico e deve articular-se com o eixo do currículo, com a docência, e com as disciplinas tendo em vista a alcançar o objeto do projeto de formação com ênfase na pesquisa e com a relação com a realizada prática.

Para Bernstein (1988), o currículo pode ser concebido conceitualmente de dois modos, integrado ou coleção. O currículo de tipo integrado não possui nítidos limiares entre os conhecimentos; dessa forma, possui uma relação aberta, flexível entre eles. $\mathrm{O}$ currículo do tipo coleção é rígido e possui uma relação fechada entre seus conhecimentos, que são delimitados e isolados. Já o currículo tipo coleção configura-se muitas vezes como o modelo denominado por Torres Santomé (1998, p.104) de lineardisciplinar: "O currículo linear-disciplinar acaba configurando-se, na maioria dos casos como um currículo quebra cabeças ou tipo coleção, conforme a terminologia de Bernstein (1988)". O currículo linear-disciplinar é uma forma de organização clássica do conhecimento em que as disciplinas são justapostas: "Mas, sem dúvida, a forma mais clássica de organização do conteúdo, ainda predominantemente, é o modelo linear disciplinar, ou conjunto de disciplinas justapostas, na maioria das vezes de uma forma bastante arbitrária" (ibidem, p.103).

Neste tipo de currículo existe um grau da manutenção dos limites entre os conteúdos. Bernstein (idem), sobre esta questão trabalha com o conceito de classificação; se o isolamento entre as disciplinas for intenso, mais forte será a sua classificação, se o isolamento entre as disciplinas for mais fraco, sua classificação será fraca.

Pensar a Prática, Goiânia, v. 14, n. 1, p. 1-12, jan./abr. 2011 
O currículo prescrito da Instituição Formadora no projeto político-pedagógico aproxima-se do currículo tipo coleção, pois possui os limiares entre as disciplinas bem delimitados. Com a proposta das disciplinas serem espaços temáticos e da articulação entre elas e entre a docência, o grau de isolamento entre as mesmas pode tornar-se menos intenso. Mas, essa diminuição somente poderá acontecer na organização e desenvolvimento do trabalho pedagógico dos professores de forma coletiva. Isto ocorre porque, de acordo com a matriz curricular, a aproximação entre as diferentes disciplinas está condicionada através de uma aproximação entre os docentes; isso requer um trabalho coletivo bem articulado (TORRES SANTOMÉ, 1998).

Inferimos que esta organização curricular pode comprometer sobremaneira a inclusão da pesquisa como um dos princípios do currículo. Segundo Moreira (2003), a organização dos currículos no ensino superior no formato do tipo coleção acaba estimulando:

a) territórios demarcados e a visão do conhecimento como propriedade privada; b) a valorização do trabalho isolado; c) especialização de funções; d) a visão do conhecimento como sagrado e mistérios (e a conseqüente visão do aluno como ignorante, como carente de socialização na ordem existente) e; e) o uso do currículo como instrumento de controle dos sujeitos implicados (p.61).

Nesse sentido, o currículo do tipo coleção pode contribuir para um trabalho docente individualizado, em que o conhecimento é considerado estático e sua produção situando-se distante dos estudantes universitários. Já, para o mesmo autor, o currículo do tipo integrado contribui para:

[...] o desenvolvimento da capacidade de decisão do aluno, o foco na construção do conhecimento, a utilização de ideias que estabeleçam relações entre diferentes campos do saber; a valorização da estrutura profunda dos assuntos; o estabelecimento de relações mais democráticas nas salas de aula. (ibidem, p.62)

Nessa concepção, além de se estabelecerem relações mais democráticas nas salas de aula, os estudantes são considerados capazes de produzir conhecimentos e existe a possibilidade do diálogo entre os diversos campos do saber, o que contribui para o processo de inclusão da pesquisa no currículo.

André (2001) considera que, para se ter a pesquisa como eixo ou núcleo do curso, integrando o projeto de formação da instituição, como se propõe no projeto pedagógico da Instituição Formadora, a organização curricular deve estar estrategicamente articulada, de forma coletiva, em todo o processo formativo, com o objetivo de "[...] desenvolver habilidades e atitudes de investigação nos futuros professores" (p.61), seja no interior das disciplinas ou nas várias atividades acadêmicas.

Assim, em um curso de formação docente que tenha a pesquisa como eixo transversal, é importante que sua organização curricular supere a lógica fragmentada que configura o currículo do tipo coleção, recomendando-se, dessa forma, que procure estabelecer integração entre os conteúdos no sentido de aproximar-se do currículo do tipo integrado. 
Outro fator significativo ao considerar a pesquisa como elemento do currículo da formação inicial é que a formação docente deve acontecer pela e para a pesquisa. (FONTANA, 2006). Ou seja, é necessário que estudantes tenham acesso aos conhecimentos relacionados à pesquisa científica com o objetivo de serem instrumentalizados para desenvolver atividades de investigação (SEVERINO, 2001); e a pesquisa pode ser articulada juntamente com o processo de ensino (ANDRÉ, 2006).

Apesar de o projeto político pedagógico prever que a pesquisa deva estar presente em todas as disciplinas do currículo, existe algumas disciplinas que possuem uma indicação específica de inclusão da pesquisa. Essas indicações estão em seus títulos e/ou em suas ementas. São elas: a) Oficina Experimental, b) Introdução ao Pensamento Científico, c) Núcleos Temáticos de Pesquisa, d) Disciplinas que abordam conhecimentos específicos da Educação Física, e e) Estágio Supervisionado.

A Oficina Experimental é uma disciplina que utiliza a pesquisa como instrumento para investigar problemas oriundos da prática pedagógica em diversos ambientes educacionais em que a Educação Física estabelece intervenção. Seu objetivo é contribuir com a construção de projetos investigativos que apontem para ações direcionadas para a superação de problemas da prática pedagógica no campo de atuação. É ofertada anualmente, com uma carga horária de 64 horas/aula no $3^{\circ}$ e $4^{\circ}$ períodos. Aborda os campos não escolares, sendo organizada em um formato em que os estudantes devem realizar uma pesquisa de campo.

A disciplina Introdução ao Pensamento Científico é responsável por abordar conhecimentos filosóficos, epistemológicos e relacionados ao desenvolvimento de pesquisas. Está localizada no quinto período do curso e possui uma carga horária de 64 horas. Essa disciplina possui uma importância singular no currículo da Instituição Formadora, pois é responsável por tratar de conhecimentos fundamentais sobre a ciência.

A disciplina aborda conhecimentos de natureza científica a partir de uma prática histórica e dinâmica que procura superar uma concepção normativa de ciência. De acordo com Severino (2001), a inclusão da pesquisa na formação do professor em uma abordagem crítico-dialética deve abordar o conhecimento de natureza científica "como resultante de uma prática histórica, dinâmica, não como verdades definitivas" (p.20).

No projeto político-pedagógico da Instituição Formadora existe uma indicação de que as disciplinas relacionadas aos conhecimentos específicos da Educação Física (conhecimentos relacionados a ginástica, os jogos, o esporte, as lutas, a dança, o lazer, as linguagens corporais expressivas e culturais, entre outros), sejam ministradas a partir da inclusão da pesquisa ${ }^{2}$. A ideia é que a pesquisa nestas disciplinas apareça como um instrumento de reflexão e análise das práticas corporais e da produção de conhecimento.

Os Núcleos Temáticos de Pesquisa fazem parte de um componente curricular que tem o objetivo de contribuir com a elaboração dos trabalhos de conclusão de curso, relatórios de pesquisas realizadas pelos estudantes apresentados no final da disciplina em uma defesa pública perante uma banca examinadora.

\footnotetext{
${ }^{2}$ Os títulos das disciplinas ilustram bem a análise aqui apresentada. Vejamos alguns nomes: "Metodologia de ensino e pesquisa em ginástica escolar, metodologia do ensino e pesquisa em natação, metodologia de ensino e pesquisa em voleibol".
}

Pensar a Prática, Goiânia, v. 14, n. 1, p. 1-12, jan./abr. 2011 
Em um curso de licenciatura, os trabalhos de conclusão de curso possuem uma grande importância na formação dos estudantes, por permitir um olhar mais próximo da realidade a partir de um trabalho de investigação com uma maior profundidade teórica. A construção do trabalho de conclusão de curso pode constituir-se em um momento significativo de produção de conhecimento sobre o trabalho docente se for bem articulada no processo de formação inicial (ALMEIDA, 2008).

E importante, nesse processo, que a realidade do trabalho docente seja problematizada para ajudar os estudantes na compreensão dessa realidade e possa também muni-los de possibilidades de enfrentá-la.

Como o projeto pedagógico do curso de licenciatura da Instituição Formadora prevê uma perspectiva ampliada de docência, os núcleos temáticos para a construção do trabalho de conclusão de curso possuem um enfoque em quatro temas diferentes e relacionados com alguns campos de intervenção do professor de Educação Física. A partir destes temas, os estudantes escolhem um no qual será desenvolvida sua pesquisa. Os núcleos temáticos são: a) Educação Física e Escola; b) Saúde e Educação; c) Lazer e Educação; d) Educação Física e Esporte.

O Estágio Supervisionado do curso de Licenciatura em Educação Física da Instituição Formadora possui duas disciplinas anuais. As disciplinas são denominadas de Estágio Supervisionado I e II, e estão localizadas do $5^{\circ}$ ao $8^{\circ}$ períodos: o Estágio Supervisionado I, no $5^{\circ}$ e no $6^{\mathrm{a}}$ e o Estágio Supervisionado II, no $7^{\circ}$ e no $8^{\circ}$.

O objetivo geral do Estágio Supervisionado é identificar e compreender a organização do trabalho pedagógico escolar e da Educação Física escolar, propiciando a intervenção investigativa, relacionando-a com possibilidades de novas formas de ação. E, dessa forma, a pesquisa é incluída como eixo central do estágio. Essa proposta de estabelecer a pesquisa no estágio está em conformidade com autores como Almeida (2008), André (2006), Pimenta e Lima (2008) e Pimenta (2006).

O estágio do curso está organizado a partir de uma relação dialética entre a didática e o trabalho de intervenção. Assim, a Didática é parte integrante do estágio.

No primeiro momento, são realizadas aulas expositivas e discussões teóricas abordando temas relacionados com a Didática e à pesquisa, como organização do trabalho pedagógico, projeto político pedagógico, planejamento escolar, entre outros. Este momento inclui ainda discussão a respeito de alguns procedimentos de pesquisa.

No segundo momento, acontece o contato e identificação da escola campo do estágio. No terceiro momento, acontece uma realização de pesquisa de cunho etnográfico; os estudantes utilizam os seguintes instrumentos e procedimentos de pesquisa: análise documental, entrevistas, observação, questionários.

No quarto momento, os estudantes, de posse dos dados obtidos na pesquisa, vão realizar o planejamento para a prática pedagógica. Nesse período, são discutidos os princípios do planejamento, o planejamento coletivo, abordagens pedagógicas da Educação Física, momento encerrado com a apresentação e discussão coletiva da proposta de ensino elaborada pelos estudantes.

O quinto momento do trabalho do Estágio Supervisionado é a intervenção (prática pedagógica) realizada pelos estudantes na escola-campo. Após o momento de intervenção, é realizada a avaliação da prática pedagógica efetivada, quando os estudantes apresentam os problemas, as dificuldades ali encontradas e propõem possíveis formas de superação dos problemas levantados. Em seguida, os estudantes 
devem sistematizar o desenvolvimento das aulas ministradas no Estágio Supervisionado no formato de um portfólio.

Por fim, são realizados dois seminários: um na escola-campo, de forma interativa entre os professores e estudantes universitários juntamente com professores da escola, em que se realiza a avaliação geral do Estágio Supervisionado. O segundo na Instituição Formadora e visa à realização da avaliação coletiva da disciplina.

\section{Considerações finais}

Este trabalho abordou o tema pesquisa na formação docente, tendo como objetivo compreender o lugar da pesquisa no currículo de um curso de formação inicial de professores de Educação Física.

Após análise documental foi identificado que a pesquisa está incluída no projeto pedagógico da Instituição Formadora como um meio de produção de conhecimento e está posta como princípio nuclear do curso em uma relação indissociável com o ensino e a extensão em todas as disciplinas. Nesse sentido, o conceito de pesquisa da Instituição Formadora supera a perspectiva estabelecida nas Diretrizes Curriculares Nacionais, o que consideramos positivo.

No entanto sua organização curricular se aproxima de um modelo de currículo denominado por Bernstein (1988), como coleção, pois está disposto de forma fragmentada, com os limiares entre as disciplinas bem delimitados, um tipo de currículo que não favorece a inclusão da pesquisa como eixo transversal, como está posto no projeto político pedagógico do curso investigado.

Identificamos também que apesar de haver uma orientação para que, em todas as disciplinas, seja observada a indissociabilidade entre ensino, pesquisa e extensão, existem algumas disciplinas que possuem indicação específica para inclusão da pesquisa. São elas: a) Oficina Experimental, b) Introdução ao Pensamento Científico, c) Núcleos Temáticos de Pesquisa, d) Disciplinas que abordam conhecimentos específicos da Educação Física, e e) Estágio Supervisionado.

Essas disciplinas atuam na formação pela e para a pesquisa. Ou seja, é proporcionam aos estudantes acesso aos conhecimentos relacionados à pesquisa científica com o objetivo de serem instrumentalizados para desenvolver atividades de investigação (SEVERINO, 2001); e trabalham no sentido de articular a pesquisa juntamente com o processo de ensino (ANDRÉ, 2006).

Por fim, gostaríamos de ressaltar que a formação de professores com capacidade para realizar pesquisa deva ser um processo contínuo, sem fim, assim como deve ser a formação docente.

\section{Referências}

ALMEIDA. M. I. Ensino com pesquisa na licenciatura como base na formação docente. In: ENDIPE: trajetórias e processos de ensinar e aprender: lugares memórias e culturas. Livros Porto Alegre: EDIPCRS, 2008. CD-ROM.

ANDRÉ. M. Pesquisa, formação e prática docente. In: ANDRÉ, M. (Org). O papel da pesquisa na formação e na prática dos professores. Campinas: Papirus, p. 11-25, 2001 .

Pensar a Prática, Goiânia, v. 14, n. 1, p. 1-12, jan./abr. 2011 
10

10.5216/rpp.v14i1.9047

Ensinar a pesquisar: como e para quê. In: VEIGA, I. P. A. Lições de didática. Campinas: Papirus: 2006.

BERNSTEIN, B. Clases, códigos e control: hacia uma teoria de las transmisiones educativas. Ediciones Akal. Madri, 1988.

BORGES, C. M. F. O professor de educação física e a construção do saber. Campinas: Papirus, 1998.

BRASIL. Referenciais para formação de professores. Secretaria de Educação Fundamental. Brasília, 1999.

BRASIL. Conselho Nacional de Educação. Parecer $n^{0}$ 09. Diretrizes Curriculares Nacionais para a Formação de Professores da Educação Básica, em Nível Superior, Curso de Licenciatura, de Graduação Plena. Brasília, 08 de maio de 2001.

BRASIL. Conselho Nacional de Educação. Resolução $n^{0}$ 01. Diretrizes Curriculares Nacionais para a Formação de Professores da Educação Básica, em nível superior, curso de licenciatura, de graduação plena. Brasília, 18 de fevereiro de 2002.

BRASIL. Conselho Nacional de Educação. Resolução $n^{0}$ 02. Duração e a carga horária dos cursos de licenciatura, de graduação plena, de formação de professores da Educação Básica em nível superior. Brasília, 19 de fevereiro de 2002.

GAMBOA, S. S. Pesquisa em educação: métodos e epistemologias. Chapecó: Argos, 2007.

GATTI, B. A construção da pesquisa em educação no Brasil. Brasília: Líber Livro Editora, 2007.

GIMENO SACRISTÁN, J. O currículo: uma reflexão sobre a prática. $3^{\mathrm{a}}$ Ed. Porto Alegre: Artmed, 2000.

FONTANA. M. I. A prática de pesquisa: relação teoria e prática no curso de pedagogia. Dissertação (Mestrado em Educação) PUC. Curitiba, 2006.

KUENZER, A. Z. Currículo, trabalho e profissionalização docente. In: IV Colóquio Luso-Brasileiro sobre questões curriculares: currículo, teorias e métodos. Anais... Florianópolis, 2008.

LÜDKE, M.; ANDRÉ, M. E. D. A. Pesquisa em educação: abordagens qualitativas. $9^{\text {a }}$ reimpressão. São Paulo: EPU, 2005.

MIRANDA, M. de G. O professor pesquisador e sua pretensão de resolver a relação entre teoria e a prática na formação de professores. In: ANDRÉ, M. (Org). O papel da pesquisa na formação e na prática dos professores. Campinas: Papirus, 2001. 
11

10.5216/rpp.v14i1.9047

MOREIRA. A. F. Seleção e organização dos conhecimentos curriculares no ensino superior: notas para uma discussão. In: MORAES, M. C. et ali. (Orgs). Formação de Professores: perspectivas educacionais e curriculares. Porto: Editora Porto, 2003.

.O processo curricular do ensino superior no contexto atual. In: Currículo e avaliação na educação superior. VEIGA, I. P. A. e NAVES, M. L. de P. Araraquara: Junqueira e Marin, 2005.

PÉREZ GÓMEZ, A. O pensamento prático do professor: a formação do professor como profissional reflexivo. In: NÓVOA, A. (org). Os professores e a sua formação. Lisboa: Dom Quixote, 1992.

PIMENTA, S.G. Professor reflexivo: construindo uma crítica. In: PIMENTA, S.G. e GHEDIN, E. (orgs). Professor reflexivo no Brasil: gênese e crítica de um conceito. $4^{\mathrm{a}}$ ed. São Paulo: Cortez, 2006.

PIMENTA, S.G.; LIMA, M. S. L. Estágio e Docência. $3^{\text {a }}$ ed. São Paulo: Cortez, 2008.

SEVERINO, A. J. A pesquisa em educação: abordagem crítico-dialética e suas implicações na formação do educador. In: Revista Contra Pontos. Itajaí, nº 1, 2001.

SOARES JÚNIOR, N. E. O lugar da pesquisa no currículo da formação inicial dos professores de Educação Física. Dissertação (Mestrado em Educação). UnB, Brasília, 2010.

TAFFAREL, C. N. Z. A formação do profissional da educação: o processo de trabalho pedagógico e o trato com o conhecimento no curso de educação física. Tese (doutorado em educação) Campinas. Unicamp. 1993.

TAFFAREL, C. N. Z. et. al. Formação de professores de educação física para a cidade e o campo. In: Pensar a prática: revista da Faculdade de Educação Física. Goiânia: Ed. UFG. vol. 9, n.2, jul./dez, 2006

TARDIF, M.; LESSARD C.; GAUTHIER, C. Formação de professores e contextos sociais: perspectives internacionais. Porto: Rés $(\mathrm{s} / \mathrm{d})$

TORRES SANTOMÉ, J. Globalização e interdisciplinaridade: o currículo integrado. Porto Alegre: Artes Médicas, 1998.

VEIGA, I. P. A. A aventura de formar professores. Campinas: Papirus, 2009.

\section{RESEARCH INTO THE CURRICULUM OF A BASIC TRAINING COURSE FOR TEACHERS OF PHYSICAL EDUCATION}

Pensar a Prática, Goiânia, v. 14, n. 1, p. 1-12, jan./abr. 2011 


\section{Abstract}

This study aims examine the place of research in the curriculum of a course of initial teacher of Physical Education for Basic Education. To achieve this goal we seek to understand if the research is an integral component of the National Curriculum for Teacher of Physical Education for Basic Education, and analyze the design and the indication to include the established research in the political teaching of the training course. Was used as a research procedure to document analysis. The survey was conducted in a training course for physical education teachers linked to a university in the State of Goiás.

Keywords: Physical education, training, curriculum, research.

\section{INVESTIGACIÓN EN EL CURRICULUM DE UN CURSO DE FORMACIÓN INICIAL PARA PROFESORES DE EDUCACIÓN FÍSICA}

\section{Resumen}

Este estudio tiene objetivo examinar el lugar de la investigación en el curriculum de un curso de formación inicial del profesorado de Educación Física para la Educación Básica. Para lograr este objetivo que tratamos comprender si la investigación es un componente integral en las Directrices Curriculares Nacionales de Profesores de Educación Física para la Educación Básica, y analizar el diseño y la indicación para incluir la investigación establecidas en la política de enseñanza del curso. Fue utilizado como un procedimiento de investigación para documentar el análisis. La encuesta fue realizada en un curso de formación para profesores de educación física vinculados a una universidad en el Estado de Goiás.

Palabras clave: educación física, formación inicial, curriculum, investigación

Endereço para correspondência:

Néri Emílio Soares Junior

neriemiliosoaresjunior@yahoo.com.br

Universidade Estadual de Goiás.

Avenida Anhanguera

Vila Nova

74000-000 - Goiânia, GO - Brasil

Pensar a Prática, Goiânia, v. 14, n. 1, p. 1-12, jan./abr. 2011 